\title{
AUTHOR INDEX FOR VOLUME 95
}

AGRAWAL, S.; Coefficient estimates for some classes of functions associated with $q$-function theory

AIEMSOMBOON, L. and SINTUNAVARAT, W.; Two new generalised hyperstability results for the Drygas functional equation

ALAHMADI, A.; see SHI, M.

ALI, MD F. and VASUDEVARAO, A.; Logarithmic coefficients of some closeto-convex functions

ALSHAMMARI, N. A.; Mathematical modelling in nanotechnology using calculus of variations

ANDERSSEN, R. S.; see LOY, R. J.

ARNOLD, D. J.; Thin-film flow in helical channels

BALLESTER-BOLINCHES, A., BEIDLEMAN, J. C. and IALENTI, R.; Semipermutability in generalised soluble groups

BEIDLEMAN, J. C.; see BALLESTER-BOLINCHES, A.

BEN NASR, M. and ZEIDI, N.; When is the integral closure comparable to all intermediate rings

BETTADAPURA, K.; Obstruction theory for supermanifolds and deformations of superconformal structures

BOWMAN, D.; Holomorphic flexibility properties of spaces of elliptic functions

BRZDĘK, J. and WÓJCIK, P.; On approximate solutions of some difference equations

BUGEAUD, Y. and KIM, D. H.; On the expansions of real numbers in two multiplicatively dependent bases

CABRERA-SERRANO, A. M. and MENA-JURADO, J. F.; Structure topology and extreme operators

CARSTENS, C. J.; Topology of complex networks: models and analysis

CASNATI, G.; Rank two stable Ulrich bundles on anticanonically embedded surfaces

CHANG, S. J. and CHOI, J. G.; A representation for the inverse generalised Fourier-Feynman transform via convolution product on function space

CHARAK, K. S. and SHARMA, S.; Some normality criteria and a counterexample to the converse of Bloch's principle

CHOI, C.-K.; see CHUNG, J.

CHOI, J. G.; see CHANG, S. J.

CHRISTENSEN, O., KIM, H. O. and KIM, R. Y.; Characterisations of partition of unities generated by entire functions in $\mathbb{C}^{d}$

CHUNG, J., CHOI, C.-K. and CHUNG, S.-Y.; On the real-valued general solutions of the d'Alembert equation with involution

CHUNG, S.-Y.; see CHUNG, J.

COONS, M. and TACHIYA, Y.; Transcendence over meromorphic functions 
DE GIOVANNI, F. and TROMBETTI, M.; A note on groups whose proper large subgroups have a transitive normality relation

DE HOOG, F. R.; see LOY, R. J.

DENG, M.-J. and HUANG, D.-M.; A note on Jeśmanowicz' conjecture concerning primitive Pythagorean triples

DING, L.; Regression clustering using Gibbs sampler and optimal cluster number estimation

DRAGOMIR, S. S.; Operator quasilinearity of some functionals associated with Davis-Choi-Jensen's inequality for positive maps

DRAGOMIR, S. S.; see HWANG, D.-Y.

DUNG, N. V. and HANG, V. T. L.; Best proximity point theorems for cyclic quasi-contraction maps in uniformly convex Banach spaces

EZZATI, S.; Reliability-based design optimisation methods in large-scale systems

FANG, X. and NI, Q.; A new derivative-free conjugate gradient method for large-scale nonlinear systems of equations

FENG, J.; see SHI, M.

FRANCE-JACKSON, H.; see WAHYUNI, S.

GABRIYELYAN, S. S. and MORRIS, S. A.; On varieties of abelian topological groups with coproducts

GAO, J.; see SHI, M.

GRZEŚKOWIAK, M.; Explicit zero-counting theorem for Hecke-Landau zeta-functions

GUO, H.; see HUO, S.

400

HANG, V. T. L.; see DUNG, N. V.

HATTAB, H.; Positive almost periodic solutions for the hematopoiesis model via the Hilbert projective metric

HE, J.; Detecting and modelling serial dependence in nongaussian and nonlinear time series

HUANG, D.-M.; see DENG, M.-J.

HUANG, X. and TAN, D.; Mappings of conservative distances in $p$-normed spaces $(0<p \leq 1)$

HUO, S., WU, S. and GUO, H.; Polygonal quasiconformal mappings and chord-arc curves

HWANG, D.-Y. and DRAGOMIR, S. S.; Extensions of the Hermite-Hadamard inequality for $r$-preinvex functions on an invex set

IALENTI, R.; see BALLESTER-BOLINCHES, A.

KAČINSKAITÉ, R. and MATSUMOTO, K.; Remarks on the mixed joint universality for a class of zeta functions

KHAN, M. ALI and RAJAN, A. V.; On the eventual periodicity of piecewise linear chaotic maps

KIM, D. H.; see BUGEAUD, Y.

KIM, H. O.; see CHRISTENSEN, O. 
KIM, R. Y.; see CHRISTENSEN, O.

KOŁODZIEJCZYK, K. and SAŁAPATA, R.; Algebraic and geometric properties of lattice walks with steps of equal length

KONG, Y. and LIU, Z.; On pairs of Goldbach-Linnik equations

KOO, J. K., SHIN, D. H. and YOON, D. S.; Normal bases for modular function fields

KOZLOWSKI, W. M.; A purely metric proof of the Caristi fixed point theorem

LELIS, J. and MARQUES, D.; On a problem of Erdös and Mahler concerning continued fractions

LEVY-MOORE, L., NICHOLS, M. and WESTON, A.; Comparing the generalised roundness of metric spaces

LI, B. and YANG, H.; The modified quantum Wigner system in weighted $L^{2}$-space

LI, H.-X.; see TANG, C.-H.

LI, Y. and YU, J.-T.; Fixed elements of noninjective endomorphisms of polynomial algebras in two variables

LING, D.-R.; A note on asymptotic nonbases

LIU, F.; A remark on the regularity of the discrete maximal operator

LIU, Z.; see KONG, Y.

LOY, R. J., DE HOOG, F. R. and ANDERSSEN, R. S.; Convergence in relaxation spectrum recovery

LUCA, F. and STĂNICĂ, P.; Monotonic phinomial coefficients

MADRID, J.; Sharp inequalities for the variation of the discrete maximal function

MARQUES, D.; see LELIS, J.

MATSUMOTO, K.; see KAČINSKAITĖ, R.

MENA-JURADO, J. F.; see CABRERA-SERRANO, A. M.

MENG, Q.; Haagerup property for $C^{*}$-crossed products

MICHALSKA, M. and MICHALSKI, A. M.; A generalisation of the ClunieSheil-Small theorem II

MICHALSKI, A. M.; see MICHALSKA, M.

MOKHTAR, H.; A few families of Cayley graphs and their efficiency as communication networks

MOLNÁR, L.; A characterisation of central elements in $C^{*}$-algebras

MOORS, W. B. and WHITE, S. J.; An elementary proof of James' characterisation of weak compactness. II

MORRIS, S. A.; see GABRIYELYAN, S. S.

NI, Q.; see FANG, X.

NICHOLS, M.; see LEVY-MOORE, L.

PATTERSON, S.; Optimising the operational energy efficiency of an open-pit coal mine system

PELLEGRINI, M. A.; The (2,3)-generation of the special linear groups over finite fields 
RAJAN, A. V.; see KHAN, M. ALI 467

ROTH, J.; A DDVV inequality for submanifolds of warped products 495

SAŁAPATA, R.; see KOŁODZIEJCZYK, K. 338

SCHRADER, P. J.; Global analysis of one-dimensional variational problems $\quad 167$

SHARMA, S.; see CHARAK, K. S. 238

SHI, M., FENG, J., GAO, J., ALAHMADI, A. and SOLÉ, P.; On the support weight distribution of linear codes over the ring $\mathbb{F}_{p}+u \mathbb{F}_{p}+\cdots+u^{d-1} \mathbb{F}_{p} \quad 157$

SHIN, D. H.; see KOO, J. K. 384

SINTUNAVARAT, W.; see AIEMSOMBOON, L. $\quad 269$

SOLÉ, P.; see SHI, M. 157

SONPANOW, N. and VEJJAJIVA, P.; A finite-to-one map from the permutations on a set

STĂNIC $\breve{A}$, P.; see LUCA, F.

177

365

TACHIYA, Y.; see COONS, M. 393

TAN, D.; see HUANG, X. 291

TANG, C.-H. and LI, H.-X.; The connection between pseudo almost periodic functions defined on time scales and on the real line

THOMAS, D. K. and VERMA, S.; Invariance of the coefficients of strongly convex functions

TROMBETTI, M.; see DE GIOVANNI, F.

TUYÉRAS, R.; Sketches in higher category theory 164

VASUDEVARAO, A.; see ALI, MD F. 228

VEJJAJIVA, P.; see SONPANOW, N. 177

VERMA, S.; see THOMAS, D. K. 436

WAHYUNI, S., WIJAYANTI, I. E. and FRANCE-JACKSON, H.; A prime essential ring that generates a special atom 214

WANG, L.; Arithmetic properties of $(k, \ell)$-regular bipartitions 353

WATSON, T. M.; On aspects of numerical ergodic theory: stability of Ulam's method, computing Oseledets subspaces and optimal mixing 165

WESTON, A.; see LEVY-MOORE, L. 299

WHITE, S. J.; see MOORS, W. B. 133

WIJAYANTI, I. E.; see WAHYUNI, S. 214

WÓJCIK, P.; see BRZDĘK, J. 476

WU, S.; see HUO, S. 66

YANG, H.; see LI, B.

YATIGAMMANA, R. P.; Advancement of autoregressive conditional duration models involving liquidity and price dynamics $\quad 523$

YOON, D. S.; see KOO, J. K. 384

YU, J.-T.; see LI, Y. 209

YUAN, C. and ZHOU, Z.-H.; The Hilbert-Schmidt norm of a composition operator on the Bergman space 250

ZEIDI, N.; see BEN NASR, M. 14

ZHOU, Z.-H.; see YUAN, C. 250 


\section{INFORMATION FOR AUTHORS}

The Bulletin of the Australian Mathematical Society aims at quick publication of original research in all branches of mathematics. To ensure speedy publication, only articles which are sufficiently well presented, able to be published without revision, and which are judged by the Editor (often in consultation with an Associate Editor) to be competitive are refereed. This policy is in the interests of authors, as a quick rejection is better than a slow rejection. The Bulletin receives more than five times the material that can be published, therefore there are many commendable papers not accepted. Editorial decisions on acceptance or otherwise are taken quickly, normally within a month of receipt of the paper. Papers are accepted only after peer review.

Manuscripts are accepted for review with the understanding that the same work is not concurrently submitted elsewhere. For a paper to be acceptable for publication, not only should it contain new and interesting results, but also

(i) the exposition should be clear and attractive, and

(ii) the manuscript should be in publishable form, without revision.

Further information regarding these requirements may be found through our website www.austms.org.au/Bulletin. Authors are asked to avoid, as far as possible, the use of mathematical symbols in the title.

Articles should be prepared in $\mathrm{ET}_{\mathrm{E}} \mathrm{X}$ using $\mathcal{A}_{\mathcal{M}} \mathcal{S}$-LTEX packages and submitted as a PDF file via our journal management system, at www.austms.org.au/Publications/Submissions/BAustMS. This permits authors to track their papers through the editorial process. Recent versions of $\mathrm{T}_{\mathrm{E}} \mathrm{X}$ are able to produce PDF files directly. A LTTEX class file for the Bulletin can be downloaded from the website. Authors who need assistance may email the secretary of the Bulletin at editor@bulletin.austms.org.au.

Authors are advised to keep copies of all files of the submitted article; the Bulletin will not accept responsibility for any loss.

\section{EDITORIAL POLICY}

1. References. Arrange references alphabetically (by surname of the first author) and cite them numerically in the text. Ensure the accuracy of the references: authors' names should appear as in the work quoted. Include in the list of references only those works cited, and avoid citing works which are in preparation or submitted. Where the work cited is not readily accessible (for example, a preprint) a copy of the article should be included with your submission.

\section{Abstracts.}

1. Each paper must include an abstract of not more than 150 words, which should contain a brief but informative summary of the contents of the paper, but no inessential details.

2. The abstract should be self-contained, but may refer to the title.

3. Specific references (by number) to a section, proposition, equation or bibliographical item should be avoided.

3. Subject Classification and Key Words. Authors should include a few key words and phrases and one or more classification numbers, following the American Mathematical Society 2010 Mathematics Subject Classification for all codes. Details of this scheme can be found on the web at www.ams.org/msc.

4. Abstracts of PhD Theses. The Bulletin endeavours to publish abstracts of all accepted Australasian $\mathrm{PhD}$ theses in mathematics. One restriction, however, is that the abstract must be received by the Editor within six months of the degree being approved.

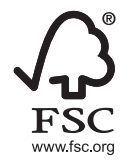

This journal issue has been printed on FSC-certified paper and cover board. FSC is an independent, non-governmental, not-for-profit organisation established to promote the responsible management of the world's forests. Please see www.fsc.org for information. 


\section{Table of Contents}

Arithmetic properties of $(k, \ell)$-regular bipartitions

Wang, $L$.

Monotonic phinomial coefficients

Luca, F. \&̈ Stănică, P.

On the expansions of real numbers in two multiplicatively dependent bases

Bugeaud, Y. Eं Kim, D. H.

Normal bases for modular function fields

Koo, J. K., Shin, D. H. \& Yoon, D. S.

Transcendence over meromorphic functions

Coons, M. \& Tachiya, 1 .

Explicit zero-counting theorem for Hecke-Landau zeta-functions

Grzeskowiak, $M$.

Extensions of the Hermite-Hadamard inequality for $\boldsymbol{r}$-preinvex functions on an invex set

Hwang, D. - Y. \& Dragomir, S. S

A representation for the inverse generalised Fourier-Feynman transform via convolution product on function space

Chang, S. 7. \& Choi, 7. G.

Invariance of the coefficients of strongly convex functions

Thomas, D. K. E Verma, S.

Coefficient estimates for some classes of functions associated with $\boldsymbol{q}$-function theory

Agrawal, $S$.

A generalisation of the Clunie-Sheil-Small theorem II

Michalska, M. EO Michalski, A. M.

On the eventual periodicity of piecewise linear chaotic maps

Khan, M. Ali \& Rajan, A. V.

On approximate solutions of some difference equations

Brzdek, f. \& Wójcik, P.

The connection between pseudo almost periodic functions defined on time scales and on the real line

Tang, C.-H. \& Li, H.-X.

A DDVV inequality for submanifolds of warped products

Roth, J.

A new derivative-free conjugate gradient method for large-scale nonlinear systems of equations Fang, X. \& Ni, Q.

Abstracts of PhD Theses

Obstruction theory for supermanifolds and deformations of superconformal structures

Bettadapura, $K$.

Holomorphic flexibility properties of spaces of elliptic functions

Bowman, D.

Regression clustering using Gibbs sampler and optimal cluster number estimation Ding, $L$.

A few families of Cayley graphs and their efficiency as communication networks

Mokhtar, $H$

Thin-film flow in helical channels

Arnold, D. F.

Advancement of autoregressive conditional duration models involving liquidity and price dynamics

Yatigammana, R. P.

Author Index for Volume 95 